University of Louisville

ThinkIR: The University of Louisville's Institutional Repository

$12-2012$

\title{
Acetaldehyde dehydrogenase 2 (ALDH2) activation protects hepatocytes from mitochondrial damage and death caused by 4-hydroxynonenal.
}

Keegan J. Baldauf 1982-

University of Louisville

Follow this and additional works at: https://ir.library.louisville.edu/etd

\section{Recommended Citation}

Baldauf, Keegan J. 1982-, "Acetaldehyde dehydrogenase 2 (ALDH2) activation protects hepatocytes from mitochondrial damage and death caused by 4-hydroxynonenal." (2012). Electronic Theses and Dissertations. Paper 63.

https://doi.org/10.18297/etd/63

This Master's Thesis is brought to you for free and open access by ThinkIR: The University of Louisville's Institutional Repository. It has been accepted for inclusion in Electronic Theses and Dissertations by an authorized administrator of ThinkIR: The University of Louisville's Institutional Repository. This title appears here courtesy of the author, who has retained all other copyrights. For more information, please contact thinkir@louisville.edu. 
Keegan J. Baldauf

B.S., Clarion University of Pennsylvania, 2005

A Thesis

Submitted to the Faculty of the

School of Medicine of the University of Louisville

In Partial Fulfillment of the Requirements

for the Degree of

Master of Science

Department of Pharmacology and Toxicology

University of Louisville

Louisville, KY

December 2012 
ACETALDEHYDE DEHYDROGENASE 2 (ALDH2) ACTIVATION PROTECTS HEPATOCYTES FROM MITOCHONDRIAL DAMAGE AND DEATH CAUSED BY 4-HYDROXYNONENAL

By

Keegan J. Baldauf

B.S., Clarion University of Pennsylvania, 2005

Thesis Approved on

August 6, 2012

by the following Thesis Committee:

Gavin E. Arteel, Ph.D.

Nobüyuki Matoba, Ph.D.

Kenneth E. Palmer, Ph.D. 


\section{ACKNOWLEDGEMENTS}

I am extremely grateful to my mentor, Dr. Gavin Arteel. Without his patience and guidance this

thesis would not be possible. I would also like to acknowledge my family and my wife Kristin who encouraged me to go back to graduate school. 


\title{
ABSTRACT \\ ACETALDEHYDE DEHYDROGENASE 2 (ALDH2) ACTIVATION PROTECTS HEPATOCYTES FROM MITOCHONDRIAL DAMAGE AND DEATH CAUSED BY 4-HYDROXYNONENAL
}

\author{
Keegan J. Baldauf
}

August 6, 2012

Alcoholic liver disease (ALD) ranks among the major causes of morbidity and mortality in the world and effects millions of patients each year. Progression of ALD is well characterized and is actually a spectrum of liver diseases, which progresses from steatosis, to inflammation and necrosis, to finally fibrosis and cirrhosis. However, the underlying mechanism(s) of ALD are not as well understood, and as a result there is no FDA-approved therapy to prevent or reverse the disease. With a better understanding of the mechanism(s) and risk factors that mediate the initiation and progression of ALD, a targeted therapy can be developed to treat or prevent it. The regenerative capacity of the liver is inhibited in fibrosis and cirrhosis. By enhancing the regenerative ability of the liver we may be able to reverse the effects of ALD. Indeed, recent in vivo studies by this group indicate that activating Aldehyde Dehydrogenase 2 (ALDH2) with Alda1 (a novel ALDH2 activator) or Ethanol $(\mathrm{EtOH})$ protects against oxidative stress and damage to the liver, as result enhancing regeneration. Because $\mathrm{ALDH} 2$ can protect mitochondria from oxidative stress that results from partial hepatectomy, oxidative stress from other sources should be protected against as well. To test this hypothesis, primary hepatocytes were isolated from mice and plated on 96-well plates for analysis via Cellomics High Content Screening. Some mice were administered $\mathrm{EtOH}$ for 3 days prior to hepatocyte isolation or exposed to Alda-1 to activate

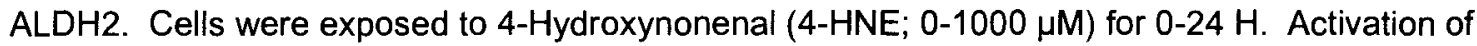
ALDH2, by pretreatment with EtOH or Alda-1 preexposure, clearly protected isolated hepatocytes from 4-HNE toxicity. Mitochondrial membrane potential was significantly increased in cells with 
activated ALDH2 and membrane permeability was decreased in these cells as well. These changes in hepatocyte viability indicate that activation of ALDH2 protects cells from oxidative stress. 


\section{TABLE OF CONTENTS}

PAGE

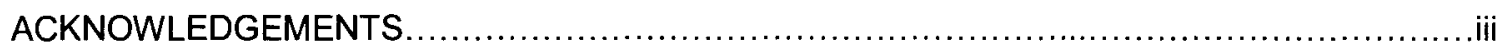

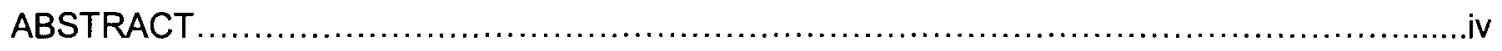

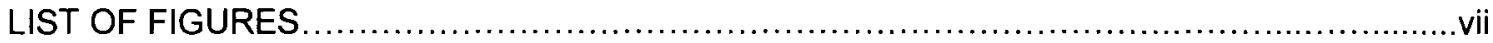

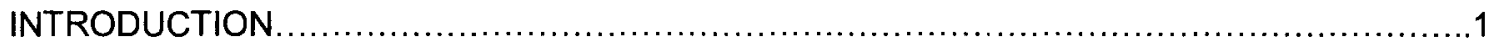

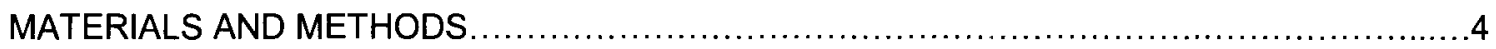

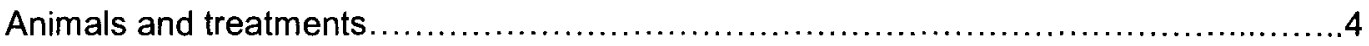

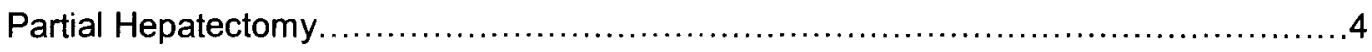

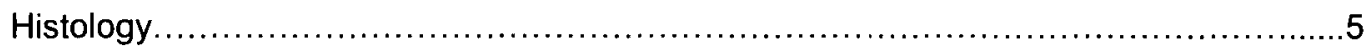

Enzymatic assay for aldehyde dehydrogenases...................................... 5

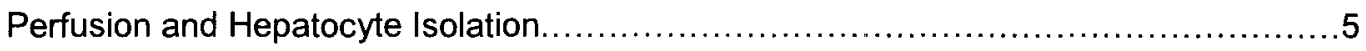

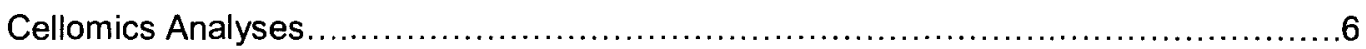

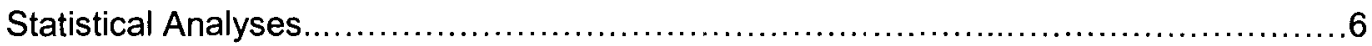

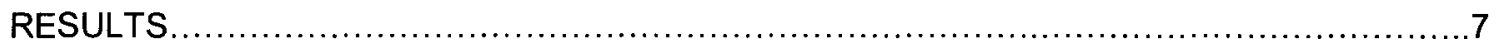

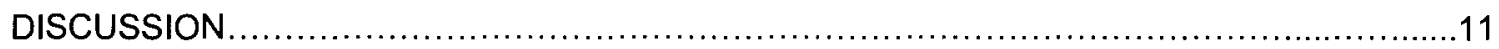

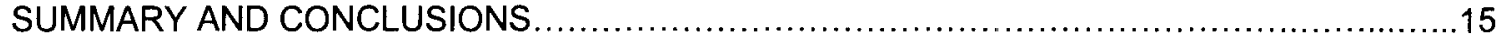

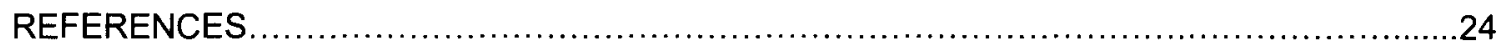

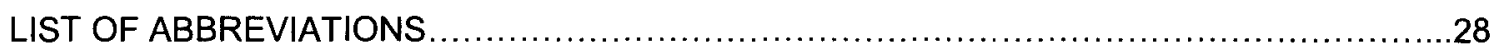

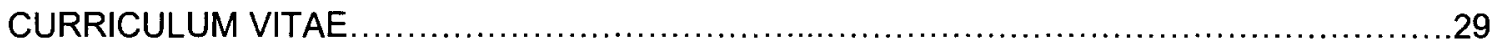




\section{LIST OF FIGURES}

FIGURE

PAGE

1. Summary of results from acute ethanol administration .......................................

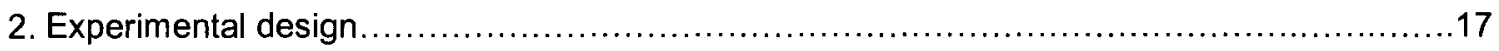

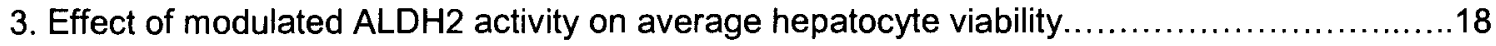

4. Representative composite photomicrographs (20x) depicting individual cell analyses...........19

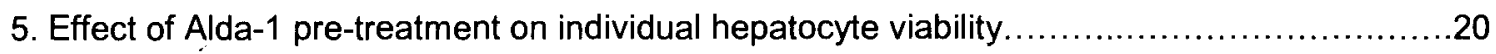

6. Effect of EtOH pre-exposure on individual hepatocyte viability following $24 \mathrm{H}$ incubation with

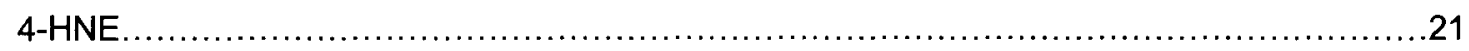

7. Representative composite photomicrographs (20x) depicting individual cell analyses.........22

8. Proposed method of ALDH2 protection from oxidative injury ................................. 


\section{INTRODUCTION}

Alcoholic liver disease (ALD) ranks among the major causes of morbidity and mortality in the world and affects millions of patients each year. ${ }^{1}$ Progression of ALD is well characterized and is actually a spectrum of liver diseases, from steatosis, to inflammation and necrosis, to finally fibrosis and cirrhosis. ${ }^{2}$ However, the underlying mechanism(s) of ALD are not as well understood, and as a result there is no FDA-approved therapy to prevent or reverse this disease. With a better understanding of the mechanism(s) and risk factors that mediate the initiation and progression of $A L D$, a targeted therapy can be developed to treat or prevent it.

The liver has tremendous regenerative capacity; which distinguishes it from other vital organs (e.g., the brain, heart and lungs) which are not as readily able to replace functional tissue that has been lost. In experimental models, the liver was able to regenerate from partial hepatectomy (PHx) from 5 to 8 days in rodents. ${ }^{3}$ Hepatocytes rarely proliferate in healthy adults but following $70 \% \mathrm{PHx}$, hepatocytes divide once or twice before returning to a quiescent state. ${ }^{4}$ The ability of the liver to regenerate is a process which requires interplay between several pathways (cytokines, growth factors and metabolic networks). ${ }^{5}$ Changes in any one of these pathways can impair the ability of the liver to regenerate from injury. The regenerative capacity of the liver is inhibited in fibrosis and cirrhosis. ${ }^{6}$ Therefore, enhancing hepatic regeneration could be an effective strategy to prevent the progression of ALD.

Aldehyde dehydrogenase $2(\mathrm{ALDH} 2)$ is a mitochondrial enzyme that oxidizes acetaldehyde to acetic acid, which is the final step in EtOH oxidation. ${ }^{7.8}$ A polymorphism of ALDH2 (ALDH2*2) is a common variant with decreased activity. ALDH2*2 heterozygous individuals have significantly higher acetaldehyde levels after ingestion of $\mathrm{EtOH}^{.}{ }^{9}$ It is known that ALDH2 loss-of-function polymorphisms increase the relative risk of developing ALD. ${ }^{9}$ Given the known toxicity of acetaldehyde, this risk association with alcohol consumption is not necessarily 
surprising. However, the same polymorphism also increases the risk of development of other chronic liver diseases [e.g., HCC and NAFLD ${ }^{10,11,12}$ ]. These data suggest that other factors besides alcohol metabolism may contribute to the increased risk of the development of liver disease in patients with the ALDH2 polymorphism.

In preliminary studies, our group has shown acute administration of ethanol activates ALDH2 which enhances hepatic regeneration (Figure 1). Furthermore, treatment with Alda-1, an ALDH2 activating compound, mimicked the effects of acute $\mathrm{EtOH}$ preexposure and treatment with Daidzin (ALDH2 inhibitor) prevented the EtOH effect. These results support the hypothesis that activation of ALDH2 enhances hepatic regeneration. Lipid peroxides are byproducts of $\mathrm{PHx}$ that cause mitochondrial damage which can lead to blunted regeneration. ${ }^{13}$ It is hypothesized that pretreatment with $\mathrm{EtOH}$ activates ALDH2 and attenuates the increased lipid peroxidation seen following $\mathrm{PHx}$ in these studies. By elucidating this mechanism we can develop new therapies based on targeting ALDH2 to enhance hepatic regeneration.

To that end, we employed Cellomics Array Scan High Content Screening (HCS) to evaluate this protective effect against hepatotoxicity induced by lipid aldehydes in isolated hepatocytes. Cellomics HCS used a 96-well plate design to analyze cell parameters via fluorescent dyes and allows for both visualization and quantification of the fluorescence. O'Brien et al reported that using HCS they were able to predict hepatotoxicity sensitivity at $93 \%$ and specificity at $98 \%$ for known compounds. ${ }^{14}$ These results showed a marked increase in sensitivity from other conventional cytotoxicity assays for human hepatotoxicity. The authors hypothesized most cytotoxicity assays measure one endpoint, whereas there are many mechanisms for toxicity. Cellomics HCS allows us to evaluate several parameters which include inner mitochondrial membrane potential, cell membrane permeability and nuclear size that can be indicative of hepatotoxicity. We employed this method to evaluate whether modifying ALDH2 activity would alter the above mentioned parameters.

4-Hydroxynonenal (4-HNE) is a lipid aldehyde that is toxic to cells and studies have shown that it is implicated in the pathogenesis of an extensive list of diseases including alcoholic liver disease. ${ }^{15}$ The lipid aldehyde is derived from n-6 polyunsaturated fatty acids (PUFAs) (e.g., 
linoleic acid, linolenic acid and arachidonic acid). ${ }^{16}$ Metabolism of 4-HNE to 4-hydroxynon-2enoic acid (4HNA) is catalyzed by ALDH2; an enzyme which can also be inactivated by high concentrations of 4-HNE. ${ }^{17,18}$ The inner mitochondrial membrane (IMM) is composed of a high concentration of PUFAs which renders it susceptible to oxidative stress and the generation of 4$\mathrm{HNE} .{ }^{19}$ By modulating the activity of ALDH2, thus altering metabolism of 4-HNE, we attempted to build on the effects seen in our whole animal model previously. 


\section{MATERIALS AND METHODS}

\section{Animals and treatments}

Male C57BL/6J mice (6-8 weeks old) were purchased from Jackson Laboratory (Bar Harbor, ME). Mice were housed in a pathogen-free barrier facility accredited by the Association for Assessment and Accreditation of Laboratory Animal Care, and procedures were approved by the local Institutional Animal Care and Use Committee. Food and tap water were allowed ad libitum.

In experiments designed to test the effects of EtOH on 4-HNE toxicity, 2 mice per group were administered $\mathrm{EtOH}$ ( $6 \mathrm{mg} / \mathrm{kg}$ i.g. diluted in water) or, an isocaloric/isovolumetric contol, Maltose-Dextrin (MD) for 3 days q.a.m. Hepatocytes from the mice were isolated $24 \mathrm{H}$ after the last i.g. dosing and seeded on 96 well plates $(10,000$ cells/well) for analysis by Cellomics HCS (Fig. 2). The hepatocytes from each mouse were plated across 2 rows of the 96-well plate for analysis. This allows duplicate wells from each mouse at each concentration of 4-HNE. In experiments designed to test the protective effects of Alda-1 on 4-HNE exposure, hepatocytes were isolated from mice and seeded on 96-well plates at a density of 10,000 cells/well (Fig. 2). Each 96-well plate consisted of hepatocytes isolated from a single mouse for the Alda-1 experiments. To analyze the inhibitory effect of Daidzin on Alda-1-mediated activation of ALDH2 the plate design mirrored that of the Alda- 1 experiments.

\section{Partial Hepatectomy}

Results in Figure 1 were from Ding et al (in publication) in which seventy percent partial hepatectomies were performed as described by Greene and Puder, with minor modifications. ${ }^{20}$ Briefly, anesthesia was initiated and maintained with isoflurane ( $2 \%$ with $2 \mathrm{~L} / \mathrm{min} \mathrm{O}_{2}$ flow). A vertical midline incision was made in the skin of the abdomen from the xiphoid cartilage extending 
to the midabdomen. The falciform ligament above the median lobe was cut just proximal to the superior vena cava. The left lateral and median lobes were ligated with 4-0 silk and cut away from the liver using microsurgery scissors. Mice were anesthetized with ketamine/xylazine $(1000 / 15 \mathrm{mg} / \mathrm{kg}, \mathrm{i} . \mathrm{m}$.$) at time of sacrifice.$

\section{Histology}

The capacity of liver regeneration was assessed by proliferating-cell-nuclear-antigen (PCNA) staining in Ding et al (in publication). PCNA staining employed a monoclonal mouse antiPCNA clone PC10 (Dako, Glostrup, Denmark) and a peroxidase-linked secondary antibody and diaminobenzidine (ARK peroxidase for mouse primary antibodies, DAKO, Carpinteria, CA). Cell cycle progression (per 1,000 hepatocytes) was estimated via PCNA staining as described previously. $^{21}$

\section{Enzymatic assay for aldehyde dehydrogenases}

Liver samples for total ALDHs activity were homogenized in RIPA buffer $[20 \mathrm{mM} \mathrm{Tris/Cl,}$ pH 7.5, $150 \mathrm{mM} \mathrm{NaCl}, 1 \mathrm{mM}$ EDTA, $1 \mathrm{mM}$ EGTA, 1\% (w/v) Triton X-100], containing protease and phophatase inhibitor cocktails (Sigma, St. Louis, MO). Mitochondrial protein for the ALDH2 activity assay was extracted from the liver, as described by Wiekowski et al. ${ }^{22}$ This work was performed by Ding et al (in publication).

\section{Perfusion and hepatocyte isolation}

A vertical midline incision was made in the skin of the abdomen from the xiphoid cartilage extending to the midabdomen. The inferior vena cava (IVC) was exposed and a $20 \mathrm{G}$ catheter was inserted into the vein. Ethylene glycol tetraacetic acid (EGTA) solution was perfused through the liver at a rate of $5 \mathrm{~mL} / \mathrm{min}$ and the portal vein was cut to allow the perfusion fluid to exit the liver. Immediately following the cutting of the portal vein the chest cavity is opened and the suprahepatic IVC was clamped. EGTA solution was perfused through the liver $(5 \mathrm{~mL} / \mathrm{min})$ for 5 minutes under a heat lamp. Following the EGTA solution, a collagenase solution containing 
collagenase $\mathrm{D}$ will be perfused through the liver for 8 minutes under a heat lamp. All perfusates were kept at $40^{\circ} \mathrm{C}$ prior to perfusion through the liver. Following the perfusion with collagenase solution containing collagenase $\mathrm{D}$, the liver was removed and minced in media on ice. The cells were filtered through a sterile BD Falcon nylon cell strainer $(70 \mu \mathrm{m})$ and placed in a $50 \mathrm{~mL}$ polypropylene conical tube. The tube was spun in a centrifuge at $400 \mathrm{rpm}$ for $5 \mathrm{~min}$ at $4^{\circ} \mathrm{C}$. The supernatant was removed and hepatocytes were resuspended in Hanks Balanced Salt Solution (HBSS) and Percoll Solution and spun at $400 \mathrm{rpm}$ for 20 minutes at $4^{\circ} \mathrm{C}$. The supernatant following this spin was removed prior to suspending the remaining hepatocytes in HBSS and spun again at $400 \mathrm{rpm}$ for 5 minutes at $4^{\circ} \mathrm{C} 2$ times. An aliquot was taken prior to the second spin and cell viability was assessed using Trypan blue staining of dead cells. Perfusions performed in which cell viability was less than $85 \%$ were not included in supplemental experimental steps.

\section{Cellomics Analysis}

Hepatocytes were seeded on a 96 -well plate at 10,000 cells/well in $100 \mu \mathrm{L}$ of media and incubated at $37^{\circ} \mathrm{C}$ in $5 \% \mathrm{CO}_{2}$ for $24 \mathrm{H}$ to allow attachment of the cells to the plate. For the Alda-1 experiments, hepatocytes were preincubated with Alda-1 $(1.52 \mu \mathrm{M})$ and/or Daidzin $(60 \mu \mathrm{M})$ for 1 $\mathrm{H}$ prior to exposure to $4-\mathrm{HNE}$ from 4 to $24 \mathrm{H}$. $4-\mathrm{HNE}$ is a lipid aldehyde that is a major product of lipid peroxidation and is toxic to cells. ${ }^{17}$ The concentration of Alda-1 used for the experiments was determined by performing a series of dose range finding studies. After the exposure period the media was removed and media containing dyes to assess cell function: Hoechst (nuclear area), TMRM (mitochondrial membrane potential), and TOTO-3 (plasma membrane permeability) were added. The plate was assessed via the Cellomics Array Scan HCS (Pittsburgh, PA).

\section{Statistical analyses}

Summary data are means \pm SEM. One-way analysis of variance (ANOVA) ANOVA with Bonferroni's post-hoc test or the Mann-Whitney rank sum test was used for the determination of statistical significance among treatment groups, as appropriate. $a, p<0.05$ compared to MD control; $b, p<0.05$ compared to MD control of the same time point after $\mathrm{PHx}$. 


\section{RESULTS}

\section{Method Development}

The first phase of our method development involved generating a protocol for hepatocyte isolation that yielded greater than $85 \%$ viability. The $85 \%$ viability threshold was established from previous literature on murine hepatocyte isolation. ${ }^{23,24}$ We chose to analyze hepatocytes that were incubated no longer than $48 \mathrm{H}$ based on literature that noted altered hepatocyte function and morphology approximately 4 days after isolation. ${ }^{25,26,27}$ The hepatocytes were plated at a density of 10,000 cells/well in 96 -well plates based on experiments performed in the laboratory employing the Cellomics HCS.

Initial experiments performed with the Cellomics HCS used factory recommended fluorescent dye concentrations as follows: Hoechst $(0.8 \mu \mathrm{M}), \operatorname{TMRM}(0.020 \mu \mathrm{M})$, TOTO-3 $(1 \mu \mathrm{M})$ and Flou-4 $(1 \mu \mathrm{M})$. It is imperative to have a well-defined nuclear area, because all Cellomics HCS acquisition data are determined from the presence of a nucleus. In our initial experiment the Cellomics HCS was unable to acquire nuclei because the concentration of Hoechst in the media was too low. This was a result of the hepatocytes' ability to export Hoechst by an ABC transporter. ${ }^{28}$ To counter the efflux of Hoechst we experimented with multiple concentrations of Hoechst dye and determined that a final concentration of $12.5 \mu \mathrm{M}$ Hoechst would be used for all experiments discussed in the results. Additionally, we found that Flou-4 (excitation $475 \mathrm{~nm}$ and emission $515 \mathrm{~nm}$ ) could not be evaluated because of the high background created from flavonoids (excitation $468 \mathrm{~nm}$ and emission $525 \mathrm{~nm}$ ) present in the hepatocyte plasma membrane. ${ }^{29}$ Based on this information and the excitation and emission parameters from the other fluorescent dyes we elected to remove this dye from our analyses.

The next step was to determine a test compound to evaluate if ALDH2 modulation could alter hepatocyte toxicity. 4-HNE has been associated with several hepatic diseases, is a product 
of oxidative stress in the liver, and is a known inactivator of ALDH2. ${ }^{30,31}$ Additionally, 4-HNE was an endpoint for the evaluation of Alda-1 which was used to enhance ALDH2 activity. ${ }^{32}$ Early experiments employed a 96-well plate design with a serial dilution (1:2) of 4-HNE ranging from 1 $\mathrm{mM}$ down to $1.9 \mu \mathrm{M}$ and control wells $(0 \mu \mathrm{M})$. This range allowed us to show a range from no effect $(0 \mu \mathrm{M})$ through total hepatocyte killing $(500 \mu \mathrm{M})$.

Alda-1 is a small-molecule activator of ALDH2 which was developed in the Mochly-Rosen Laboratory. ${ }^{32}$ Based off of the methods from the Mochly-Rosen Laboratory, we selected a range of concentrations to pursue that encompassed all of the test concentrations previously used. ${ }^{32,33}$ We determined that in our hands a concentration of $1.52 \mu \mathrm{M}$ Alda-1 was the most efficient concentration. As the concentration increased, we saw no additive effect on protection and an increasing amount of background fluorescence.

Daidzin, which inactivates ALDH2, was also incubated with hepatocytes to determine if it would blunt Alda-1 protection or increase cell death at lower concentrations of 4-HNE. Daidzin had previously been used in experiments with Alda-1 and was found to have an overlapping binding site near the exit of the substrate tunnel. ${ }^{33}$ After searching the literature we determined that a concentration of $60 \mu \mathrm{M}$ of Daidzin was appropriate for the purpose of the experiments. ${ }^{33,34}$

Following the development of the techniques mentioned above we were able to perform our experiments. The isolation and initial incubation of hepatocytes was similar regardless of the method by which we activated ALDH2. EtOH pretreatment was performed prior to hepatocyte isolation and the addition of Alda-1 and Daidzin pretreatment was performed in vitro for the respective experiments. Addition of 4-HNE was identical regardless of pretreatment method. Analyses were performed using a protocol developed on the Cellomics HCS during the developmental phase.

\section{Increasing ALDH2 activity with Alda-1 protects hepatocytes}

Because Alda-1 is a known ALDH2 activating compound, increased ALDH2 activity should protect against exposure to higher concentrations of 4-HNE. ${ }^{32}$ Multiple concentrations of 4-HNE were tested to evaluate hepatocyte function. 
Mitochondrial membrane potential (TMRM fluorescence) was decreased in hepatocytes exposed to 4-HNE levels above $125 \mu \mathrm{M}$. Cell membrane permeability (TOTO-3 flourescence) was increased in hepatocytes treated with 125 and $250 \mu \mathrm{M}$ 4-HNE. At 24 hours after 125 and $250 \mu \mathrm{M} 4-\mathrm{HNE}$ addition, there is significantly increased mitochondrial membrane potential (TMRM fluorescence) in hepatocytes pretreated with $1.52 \mu \mathrm{M}$ Alda-1 (Fig. 3).. Additionally, cell membrane permeability (TOTO-3 fluorescence) was significantly decreased in hepatocytes pretreated with $1.52 \mu \mathrm{M}$ Alda-1 prior to 4 -HNE exposure at 125 and $250 \mu \mathrm{M}$. Representative photomicrographs (Fig. 4) of hepatocytes exposed to $250 \mu \mathrm{M}$ of 4-HNE are presented as well. Basal levels of mitochondrial membrane potential (red) and cell membrane permeability (green) are presented in the control photomicrograph. At $250 \mu \mathrm{M} 4-\mathrm{HNE}$, hepatocytes have low mitochondrial membrane potential but increased cell membrane permeability. Alda-1 (1.52 $\mu \mathrm{M})$ in the presence of $250 \mu \mathrm{M} 4-\mathrm{HNE}$ was able to rescue mitochondrial membrane potential and blunt cell membrane permeability.

Approximately $81 \%$ of cells pretreated with Alda- 1 had normal mitochondrial membrane potential (>200 AU) and low plasma membrane permeability (<200 AU). This is contrasted with $41 \%$ of cells exposed to 4-HNE meeting the same criteria (Fig. 5).

\section{Decreasing ALDH2 activity with Daidzin enhances hepatocyte death}

Daidzin is a known ALDH2 inhibitor that was employed to determine if we could block the protective effect of Alda- $1 .^{35}$ Multiple concentrations of 4-HNE were tested and the predetermined concentration of Alda-1 $(1.52 \mu \mathrm{M})$ was coincubated with Daidzin $(60 \mu \mathrm{M})$ prior to the 4-HNE exposure.

Mitochondrial membrane potential following $24 \mathrm{H}$ incubation with 125 and $250 \mu \mathrm{M} 4-\mathrm{HNE}$ in the presence of Alda-1 and Daidzin was significantly increased compared to controls on average. Interestingly, at a $250 \mu \mathrm{M}$ concentration of $4-\mathrm{HNE}$ the protective effect of Alda-1 was significantly blunted in the presence of Daidzin (Fig. 3). Cell membrane permeability was significantly decreased compared to the control group at 125 and $250 \mu \mathrm{M} \mathrm{HNE}$ incubations, however, the protection was significantly blunted when compared to hepatocytes pretreated with Alda-1 alone. 
The individual hepatocyte data showed no difference between Alda-1 and the Daidzin plus Alda-1 groups alone (Fig. 5). However, in the presence of $250 \mu \mathrm{M} 4-\mathrm{HNE} 81 \%$ of hepatocytes had normal function in the Alda-1 group compared to $65 \%$ of hepatocytes in the Daidzin plus Alda-1 group.

\section{Administration of EtOH prior to hepatocyte isolation protected hepatocytes from 4-HNE toxicity}

Mice were pretreated with EtOH prior to hepatocyte isolation to further explore the enhanced regeneration observed by this treatment previously. Multiple concentrations of 4-HNE were tested following the acute EtOH pretreatment period.

Mitochondrial membrane potential was decreased and cell membrane permeability was increased in control hepatocytes following $24 \mathrm{H}$ exposure to $125 \mu \mathrm{M} 4-\mathrm{HNE}$ (Figs. 6 and 7). Hepatocytes isolated from animals pretreated with $\mathrm{EtOH}$ were protected from the effects of 125 $\mu \mathrm{M}$ 4-HNE. Approximately $30 \%$ of hepatocytes from the control group were in a stage of cell dysfunction (i.e., <200 AU TMRM or >200 AU TOTO-3 flourescence) following $24 \mathrm{H}$ incubation with $4-\mathrm{HNE}$ while only $18 \%$ fit this criteria from the EtOH pretreatment group. 


\section{DISCUSSION}

The liver has tremendous ability to regenerate, however this regenerative ability is inhibited in fibrosis and cirrhosis. Our lab has shown that acute EtOH administration enhanced hepatic regeneration following PHx. These results led us to look more closely at ALDH2, which is key to the final step in EtOH oxidation. Lipid peroxides, which cause oxidative stress, are a product of $\mathrm{PHx}$ and are metabolized by ALDH2. Our results suggested that ALDH2 played an important role in mitigating the oxidative stress caused by $\mathrm{PHx}$, thus protecting hepatocytes from further injury and enhancing the regenerative ability of the liver.

To further explore this mechanism we employed Celiomics HCS which allowed us to look at several endpoints in isolated mouse hepatocytes (e.g. mitochondrial membrane potential and cell membrane integrity). The first goal was to show that by enhancing ALDH2 activity with Alda-1 we could protect hepatocytes from 4-HNE, a lipid peroxide. Next, we also wanted to show that addition of Daidzin (ALDH2 inactivator) could blunt the protective effect of Alda-1. Lastly, we wanted to see if the protection from acute EtOH could be replicated in the in vitro setting.

A method for evaluating primary hepatocytes with the Cellomics HCS was adapted from techniques the lab already was familiar with (i.e. liver perfusion, hepatocyte isolation, and cell culture) and a paper by O'Brien et al which evaluated HepG2 cell toxicity with the Cellomics HCS. ${ }^{14}$ We found that setting up 10,000 cells/well on 96 -well plates was able to provide a monolayer to be analyzed with the Cellomics HCS. Additionally, we determined that in primary hepatocytes Hoechst, TOTO-3, and TMRM fluorescent dyes could be analyzed but Flou-4 was not used due to high background from autofluorescence generated from the hepatocytes. ${ }^{36}$ Lastly, we were able to determine appropriate concentrations of 4-HNE, Alda-1 and Daidzin to use in our experimental design. 
The Cellomics HCS data here supported the initial hypothesis and showed a protective effect of Alda-1 when exposed to 4-HNE. At the well level as illustrated in Fig. 3, mitochondrial membrane potential was protected and cell membrane permeability was blunted when hepatocytes were pre-treated with Alda-1. These effects were also carried through to the individual cell data. These data help to illustrate the depth of analyses available with the Cellomics HCS. While the well data was able to show protection, the cell level data allows us to evaluate multiple parameters against one another. For example, we can see that the mitochondrial membrane potential begins to decrease before increase in cell membrane permeability (Figs. 5 and 6 ). This gives us insight into the mechanism behind cell death; which as expected was a result of mitochondrial injury from 4-HNE exposure. ${ }^{37}$

Co-incubation of Alda-1 and Daidzin impaired the protective effect of Alda-1 when hepatocytes were exposed to 4-HNE. Daidzin did not completely ablate the Alda-1 effect but there was a significant decrease in the mitochondrial membrane potential and increase in cell membrane permeability. This effect was seen not only at the well level but also at the individual cell level. The cell level data shows that again mitochondrial function was decreased prior to cell death. Because the binding site for Daidzin on ALDH2 overlaps the binding site for Alda-1, higher concentrations of Daidzin may lead to even further blunting of the Alda-1 protection.

Finally, although not as strong an effect, we were able to show some protection of acute EtOH pretreatment from 4-HNE toxicity. Cell death was mediated first by a loss in mitochondrial function and then a loss in membrane integrity. This is further confirmation that by enhancing ALDH2 activity we can protect mitochondrial function and in turn protect cell viability. EtOH increases ALDH2 activity by going through the intermediate step of PKC $\varepsilon$ activation, which in turn phosphorylates ALDH2, thereby increasing the activity of the enzyme. ${ }^{38,39}$ Others have shown that if $\mathrm{PKC} \varepsilon$ is not stimulated by sustained $\mathrm{EtOH}$ administration then the protection it affords is lost over time. ${ }^{40,41}$ This may account for the less dramatic protection of acute $\mathrm{EtOH}$ pre-treatment in the Cellomics HCS experiments. These results show that by increasing the activity of ALDH2, 4-HNE toxicity can be blunted. 
Although this research was performed in hepatocytes, ALDH2 is expressed at high levels in multiple tissues (i.e. brain, lung, and heart). ${ }^{42}$ Suggesting that the protective effect ALDH2 activation provides from 4-HNE toxicity may also apply to these tissues. Indeed, the initial work with Alda-1 was performed in an ischemia/reperfusion model in rat hearts. ${ }^{32}$ This work showed that by enhancing ALDH2 activity, rat hearts were protected from the ischemic injury. Importantly, the protective effect was linked to increased 4-HNE metabolism by ALDH2. Recently, the same group showed that a topical application of Alda-1 reduced the severity and delayed the onset of dermatitis resulting from irradiation. ${ }^{43}$ Again in this model, 4-HNE adducts were significantly decreased in the skin of the mice. These data show the utility of ALDH2 activation in multiple tissues and the protection afforded from increased 4-HNE metabolism.

It is becoming clear that individuals with the ALDH2*2 polymorphism are more susceptible to various diseases. ${ }^{44}$ Indeed, a link has been established between the ALDH2 ${ }^{\star 2}$ polymorphism and increased risk for developing Alzheimer's Disease. ${ }^{45}$ The authors again suggest that the inability to metabolize 4-HNE may play a causal role in the development of Alzheimer's Disease. This suggests that the higher incidence of Alzheimer's Disease in individuals with the ALDH2*2 polymorphism may be prevented by increasing the activity of the mutant ALDH2. Recently, Shea and Remington argued that we are intervening too late in the development of Alzheimer's Disease. ${ }^{46}$ Perhaps increasing the activity of ALDH2 in populations susceptible to the disease, prior to the onset of the disease, will decrease the incidence rate.

Taken together, these results show the possible utility in increasing the activity in ALDH2 to protect against various diseases. The mechanisms all link metabolism of 4-HNE (resulting from oxidative stress) by ALDH2 to protecting against the progression of the respective malady (Fig. 8). While most of the work discussed above links the ALDH2*2 polymorphism with increased incidences of disease, there may be therapeutic utility for the increased activity in ALDH2 wild-type individuals. For example, the Alda-1 experiments discussed above used animals which had the wild type ALDH2 enzyme. A possible therapeutic effect was suggested in the skin irradiation experiment for individuals exposed to high levels of radiation. If a therapeutic effect of increased ALDH2 activity is confirmed then this could provide a therapy for several 
maladies (e.g. ALD, Alzheimer's Disease, Myocardial Infarction). Thus, increasing ALDH2 activity may prove a useful tool in prevention and/or treatment of various chronic disease states. Further experiments should be performed to verify the findings presented in this document. An ALDH2 knockout mouse has been developed and used previously in published reports. $^{47,48}$ Hepatocytes from these knockout mice should be isolated and analyzed employing the methods designed here. From these follow up experiments we could determine if 4-HNE toxicity is increased in hepatocytes lacking ALDH2. Additionally, we could further confirm that Alda-1 protection is mediated through ALDH2 activation. Lastly, Daidzin inactivates ALDH2 and should therefore have no effect in ALDH2 knockout mice. The collection of these data would help to further strengthen the case that ALDH2 is key to enhancing hepatocyte viability.

Second, in order to verify our hypothesis that ALDH2 activation by acute EtOH administration protects hepatocytes from 4-HNE toxicity we could again employ the ALDH2 knockout mice. If our model is correct then no protection would be afforded to hepatocytes from these mice following acute EtOH treatment. Additionally, these mice could be used in the PHx model to evaluate liver regeneration following acute $\mathrm{EtOH}$ administration. At the present time no research has been done to characterize liver regeneration in ALDH2 knockout mice (PubMed search using the terms: ALDH2, knockout, liver and regeneration). By performing these experiments we could further understand the role of ALDH2 in protecting hepatocytes from 4HNE toxicity and determine what effect the lack of ALDH2 has on liver regeneration (in MD and EtOH pretreated mice). 


\section{SUMMARY AND CONCLUSIONS}

The final phase of ALD results in fibrosis and cirrhosis, which cause impaired hepatic regeneration. Currently there is no therapy to prevent or reverse the disease. Through further study of the disease and its mechanisms a viable therapy can be developed. To that end, the lab looked to evaluate the effects of acute $\mathrm{EtOH}$ on hepatic regeneration. It is well known that chronic $\mathrm{E} t \mathrm{OH}$ administration impairs hepatic regeneration. The finding that acute $\mathrm{EtOH}$ enhanced hepatic regeneration was very interesting and found to be associated with an increase in ALDH2 activity.

Cellomics HCS has previously been used by O'Brien et al. to show high specificity and selectivity for toxic compounds in HepG2 cells. This showed that the Cellomics HCS was indeed a very powerful tool to understand hepatotoxicity in the liver. We in turn developed a method using primary hepatocytes in the Cellomics HCS that allowed us to assess mitochondrial function and cell membrane permeability in these cells. We then used the method to expose hepatocytes to 4-HNE while modulating ALDH2 activity. We found that increasing ALDH2 activity with either Alda-1 or acute EtOH pretreatment protected mitochondrial membrane potential and cell membrane integrity. Additionally by impairing ALDH2 with Daidzin we were able to blunt the protective effect of Alda-1.

At this time there is no therapy to enhance hepatic regeneration in ALD. These data suggest that by increasing ALDH2 activity we can decrease oxidative stress. By decreasing oxidative stress perhaps we can halt or even reverse the progression of ALD. ALDH2 activation has shown promise in protecting against other injuries that result in oxidative stress as well (ischemia/reperfusion and irradiation) which shows applications outside of ALD. Additionally, increasing ALDH2 activity may be a therapeutic target for other diseases (e.g. NAFLD and Alzheimer's Disease); indicating utility for the enzyme far beyond the scope of this research. 

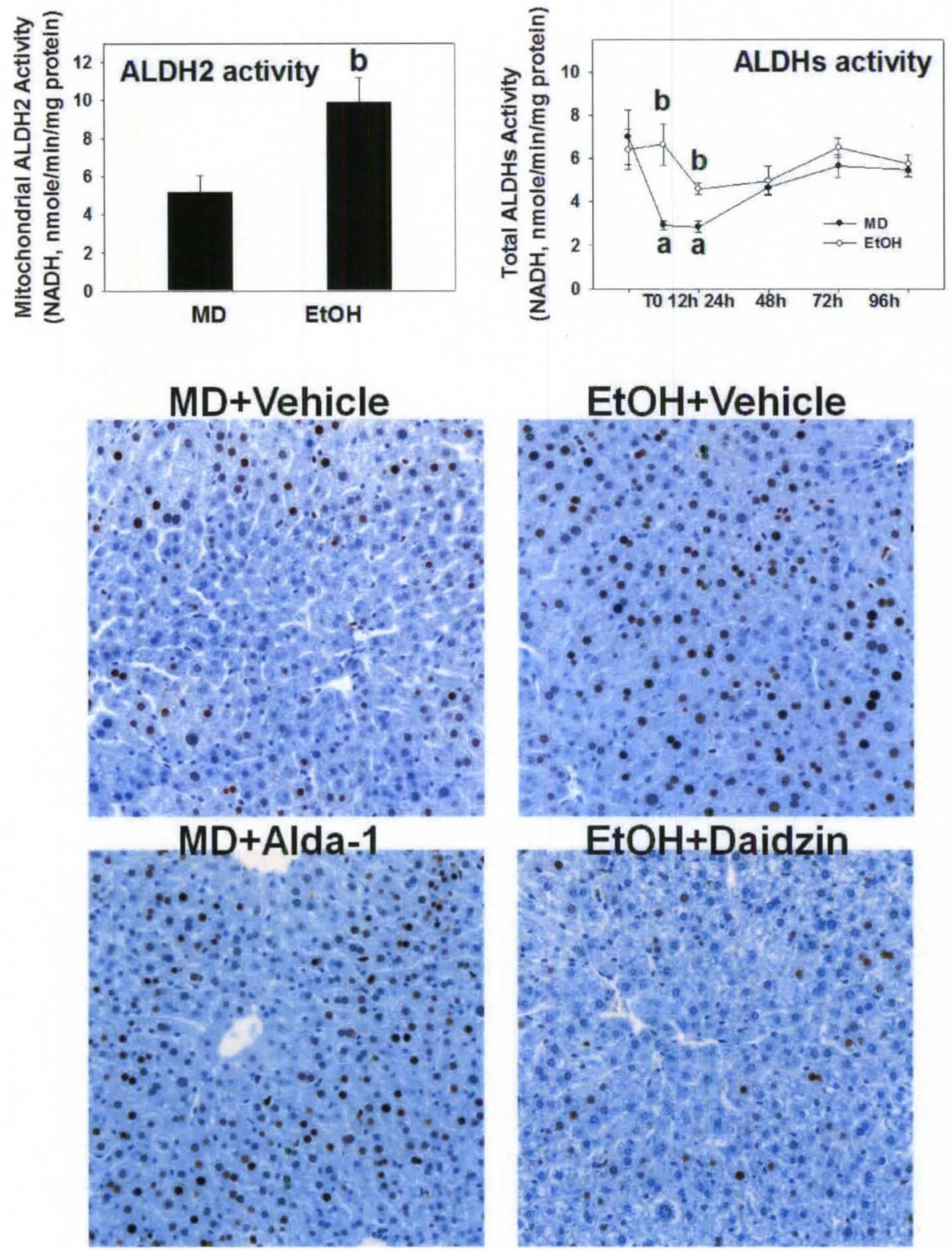

Fig. 1: Summary of results from acute ethanol administration

Male C57BL/6J mice were pretreated with maltose dextrin or ethanol for 3 days and $\mathrm{PHx}$ were performed on day 4 as described in Methods. ALDH2 and ALDHs activity were determined and PCNA immunohistochemical analysis was performed on tissue samples. Quantitative data are means \pm SEM. a, $p<0.05$ compared to time $=0 ; b, p<0.05$ compared to MD control of the same time point after PHx. 


\section{The Experiments}

Alda-1 Experiment

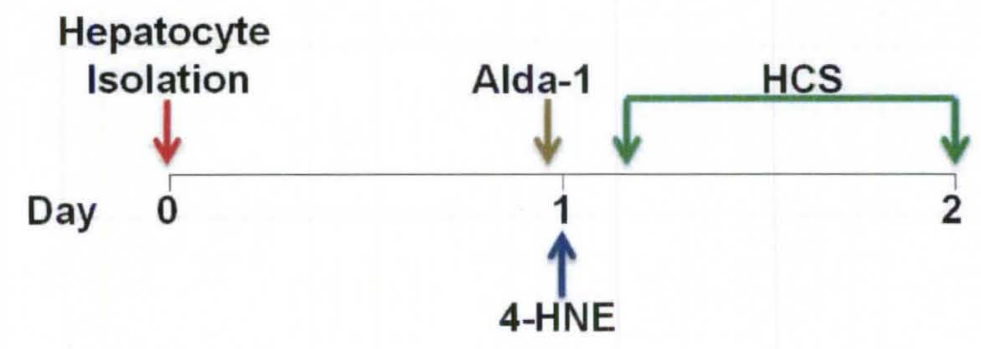

\section{EtOH Experiment}

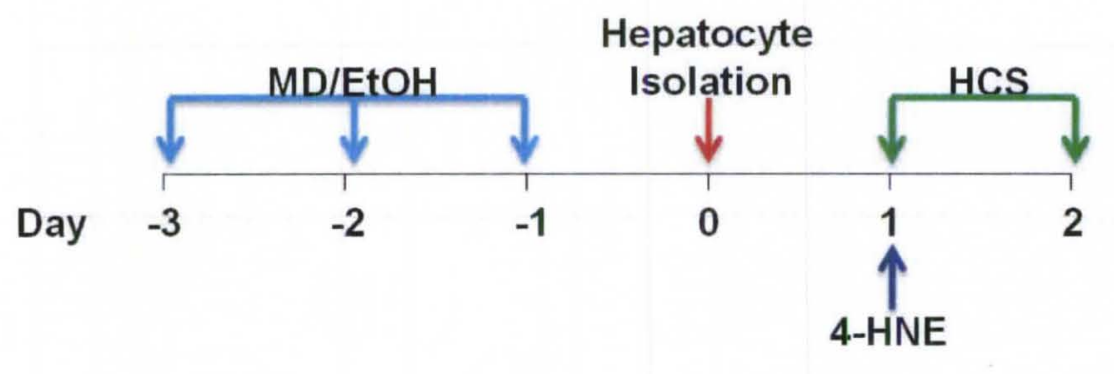

Fig. 2: Experimental Design

Hepatocytes were isolated on Day 0. For experiments using Alda-1, the hepatocytes were exposed to Alda-1 $(1.52 \mu \mathrm{M})$ for $30 \mathrm{~min}$ prior to addition of 4-HNE (0-1 mM). For experiments with EtOH pre-exposure, animals were administered $\mathrm{EtOH}$ (6 g/kg i.g.) or MD for 3 days prior to hepatocyte isolation. The hepatocytes were exposed to 4-HNE (0-1 mM) from 0-24h. At corresponding time points, fluorescent dyes were added to the hepatocytes and analyzed by HCS. 

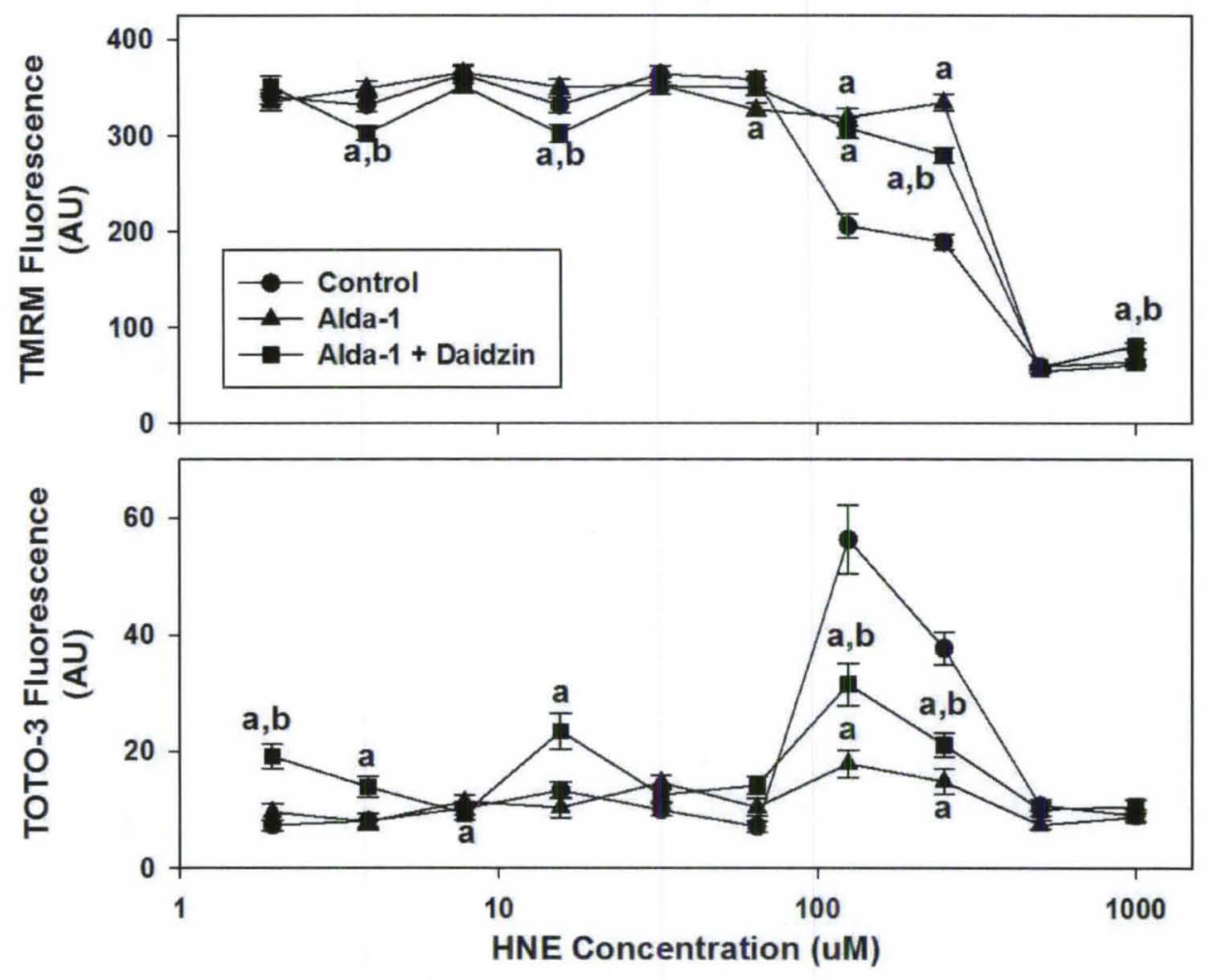

Fig. 3: Effect of modulated ALDH2 activity on average hepatocyte viability Mitochondrial membrane potential (TMRM fluorescence) and cell membrane permeability (TOTO-3) were determined using the Cellomics HCS. Hepatocyte viability data are means \pm SEM $(n=\sim 200)$. a, $p<0.05$ compared to control, $b, p$ $<0.05$ compared to Alda- 1 . 
Control

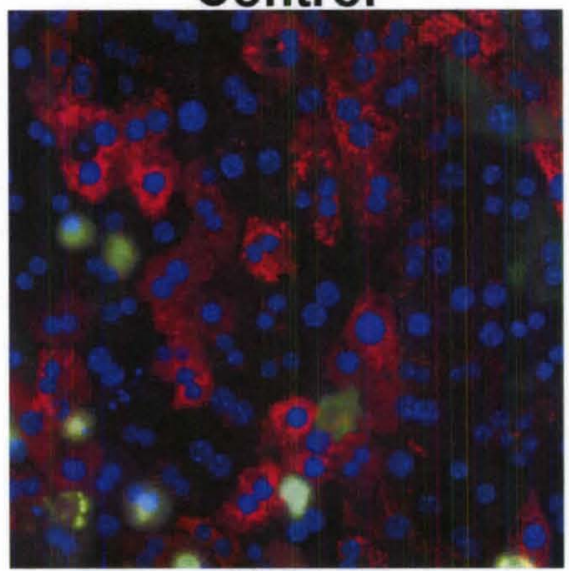

Alda-1

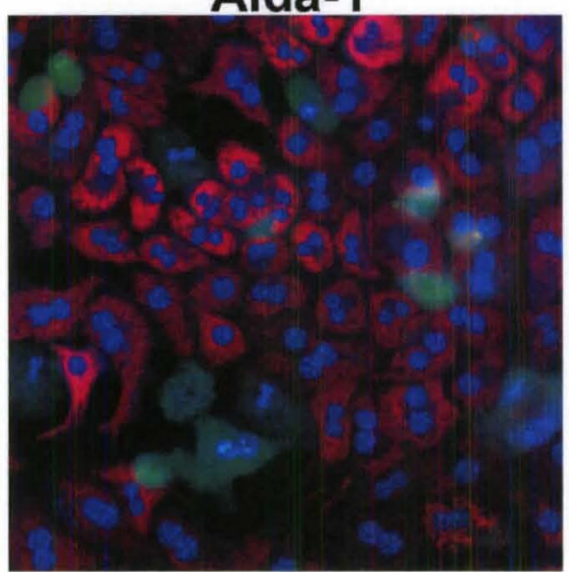

HNE

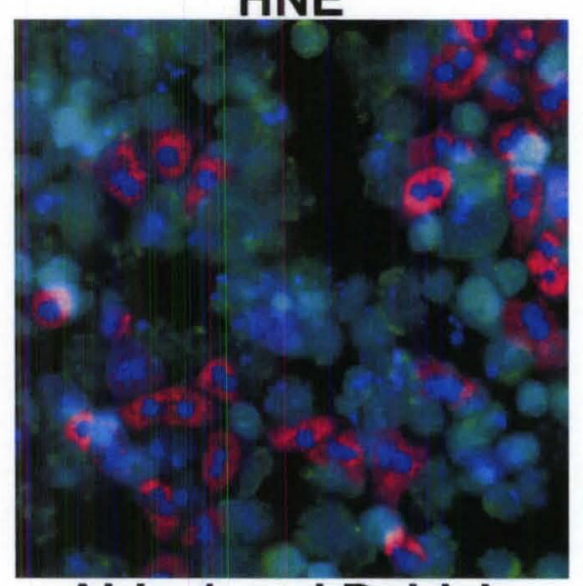

Alda-1 and Daidzin

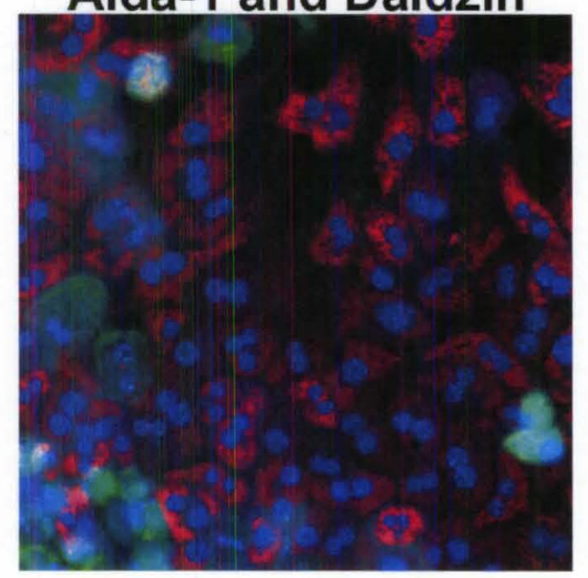

Fig. 4: Representative composite photomicrographs (20x) depicting individual cell analyses by Cellomics HCS

Nuclear fluorescence (Hoechst; blue), mitochondrial membrane potential (TMRM; red), and cell membrane permeability (TOTO-3; green). 


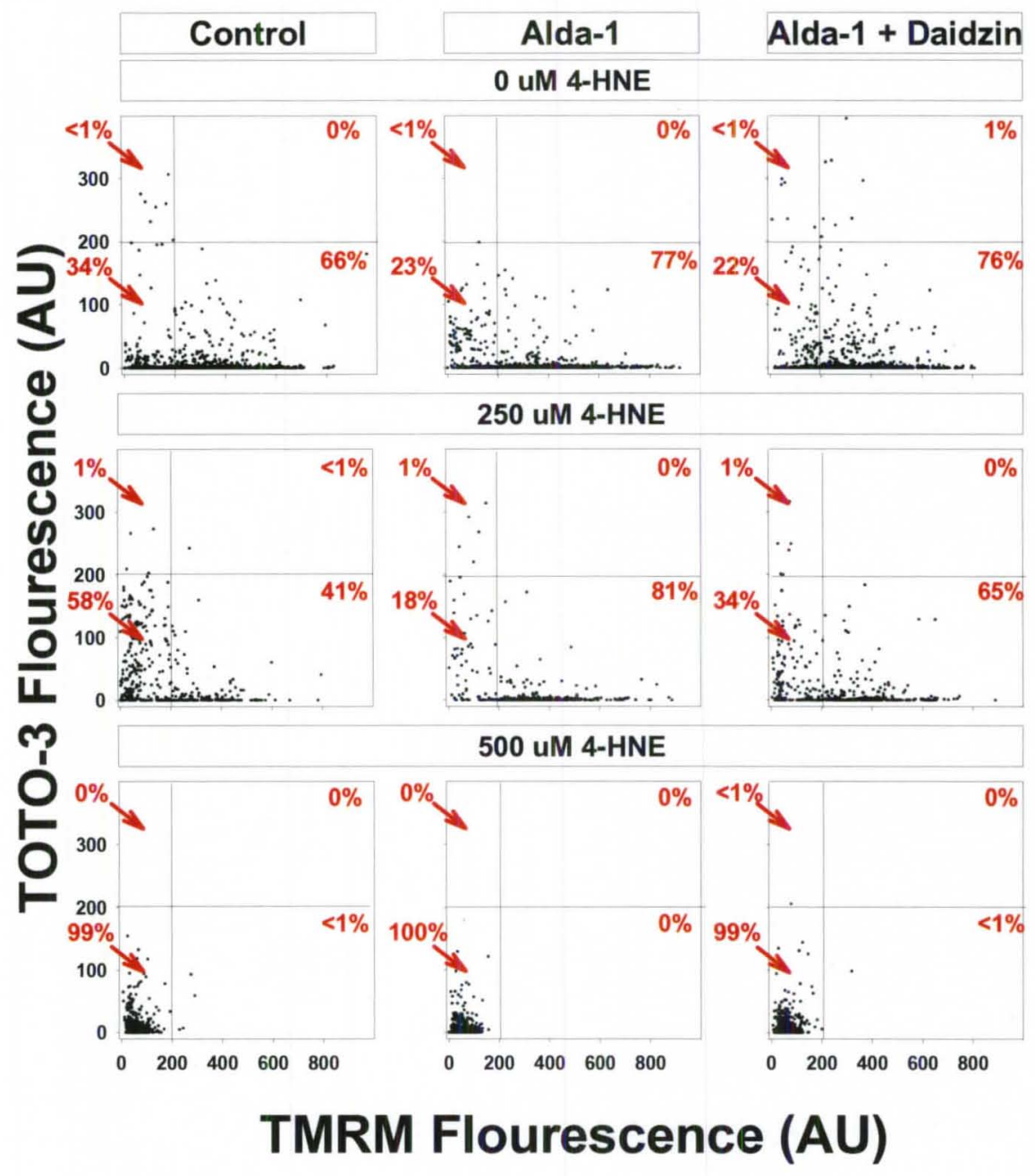

Fig. 5: Effect of Alda-1 pre-treatment on individual hepatocyte viability. Cell membrane permeability (TOTO-3) as a function of mitochondrial membrane potential (TMRM) were determined using Cellomics HCS. 


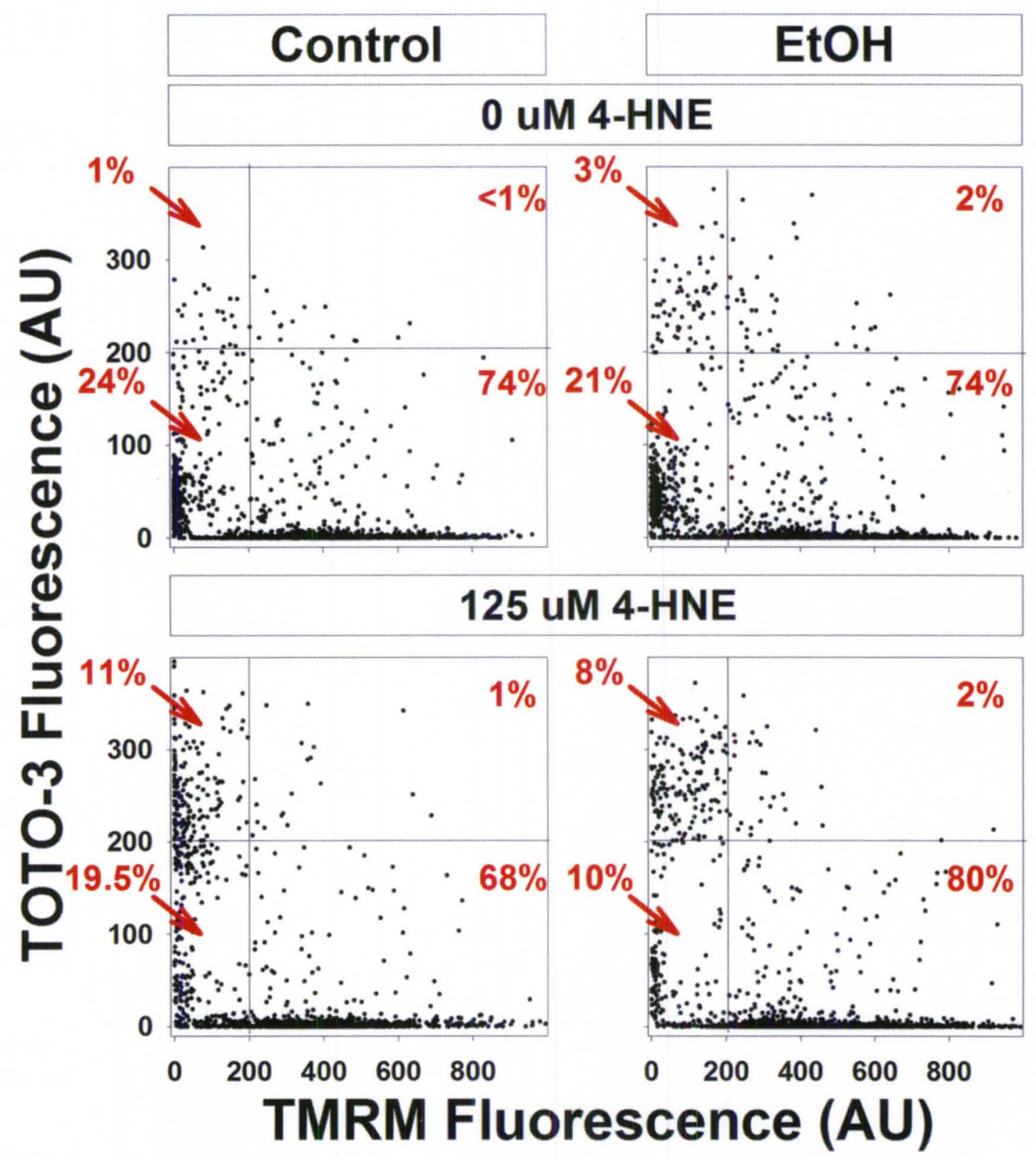

Fig. 6: Effect of EtOH pre-exposure on individual hepatocyte viability following $24 h$ incubation with 4-HNE

Individual Cell Data Analyses. Cell membrane permeability (TOTO-3) as a function of mitochondrial membrane potential (TMRM) were determined using Cellomics HCS. 

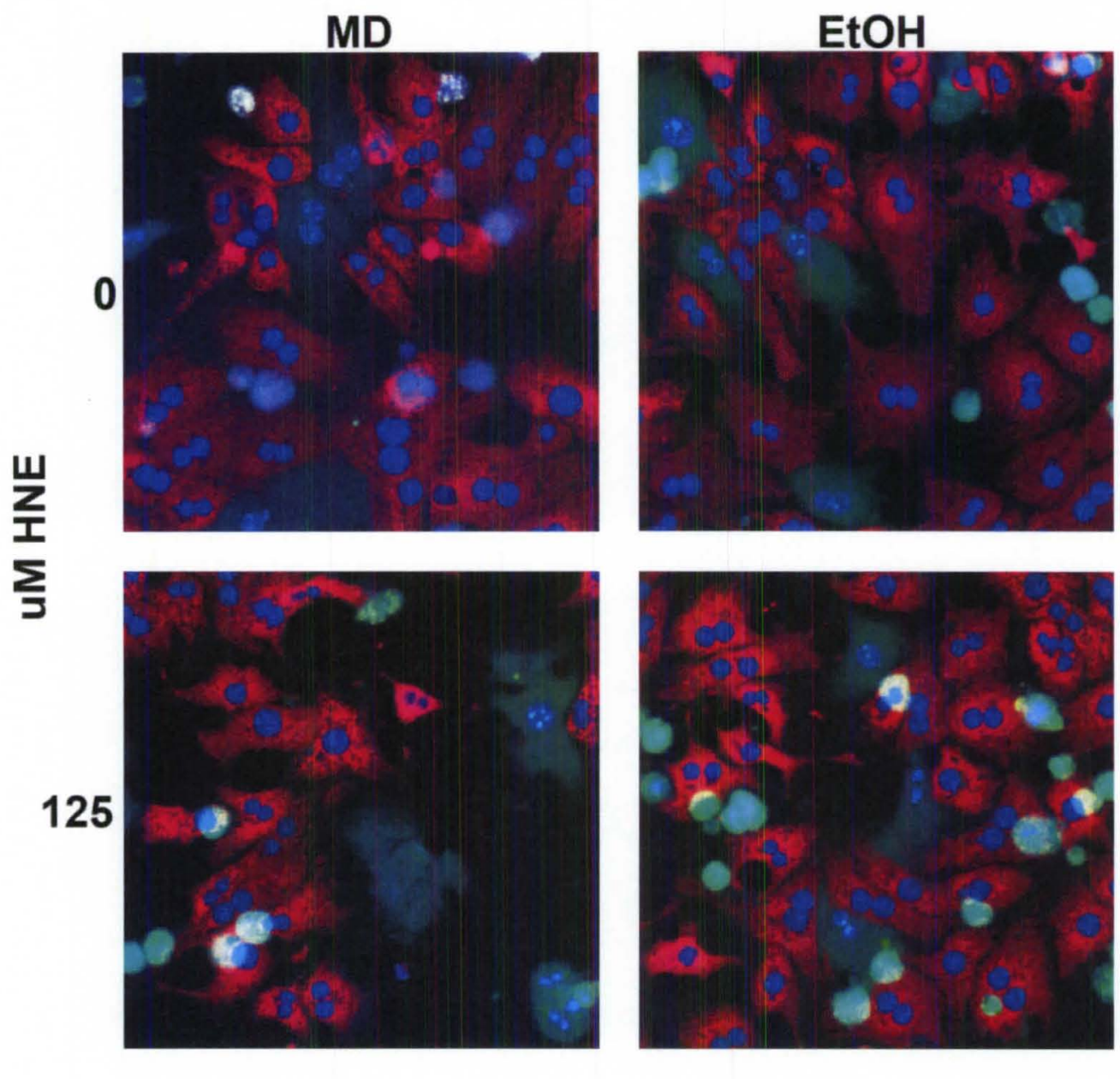

Fig. 7: Effect of EtOH pre-exposure on individual hepatocyte viability following 24h incubation with 4-HNE.

Representative composite photomicrographs (20x) depicting analyses by Cellomics HCS. Nuclear fluorescence (Hoechst; blue), mitochondrial membrane potential (TMRM; red), and cell membrane permeability (TOTO-3; green). 


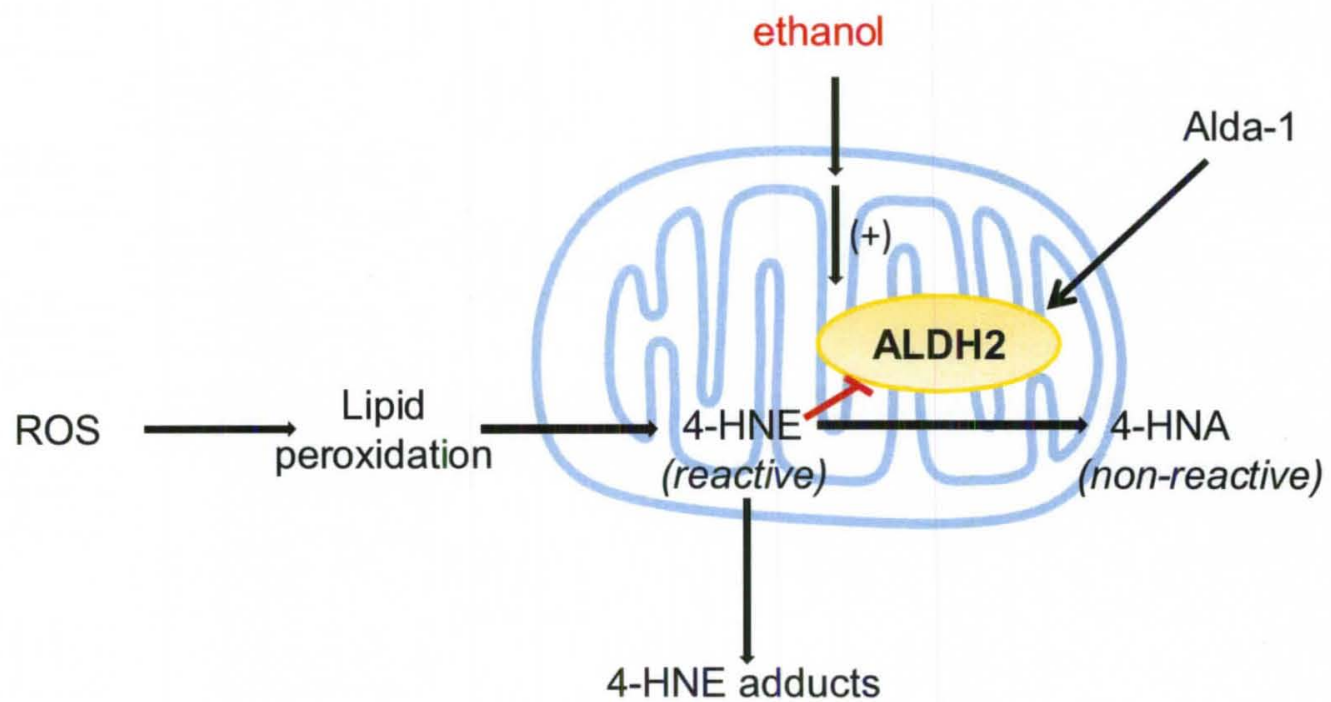

Fig. 8: Proposed mechanism of ALDH2 protection from oxidative injury Reactive oxygen species (ROS) induce lipid peroxidation which produces 4-HNE. ALDH-2 metabolizes 4-HNE to its non-reactive product 4-HNA. If ALDH2 is inactivated by high concentrations of 4-HNE then 4-HNE adducts can form and cause cell death. By pre-treating with EtOH or Alda-1 we can protect against 4-HNE toxicity by increasing ALDH2 activity. 


\section{REFERENCE LIST}

1. Grant, B. F., Dufour, M. C., and Harford, T. C. Epidemiology of alcoholic liver disease. Semin.Liver Dis. 1988 Feb; 8(1):12-25.

2. Diehl, A. M. Liver disease in alcohol abusers: clinical perspective. Alcohol 2002 May; 27(1):7-11.

3. Curado, S. and Stainier, D. Y. deLiver'in regeneration: injury response and development. Semin.Liver Dis. 2010 Aug; 30(3):288-295.

4. Fausto, N. Liver regeneration. J Hepatol 2000; 32(1 Suppl):19-31.

5. Fausto, N., Campbell, J. S., and Riehle, K. J. Liver regeneration. Hepatology. 2006 Feb; 43(2 Suppl 1):S45-S53.

6. Rudolph, K. L., Chang, S., Millard, M., Schreiber-Agus, N., and Depinho, R. A. Inhibition of experimental liver cirrhosis in mice by telomerase gene delivery. Science. 2000 Feb 18; 287(5456):1253-1258.

7. Marchitti, S. A., Brocker, C., Stagos, D., and Vasiliou, V. Non-P450 aldehyde oxidizing enzymes: the aldehyde dehydrogenase superfamily. Expert.Opin.Drug Metab Toxicol. 2008 Jun; 4(6):697-720.

8. Budas, G. R., Disatnik, M. H., and Mochly-Rosen, D. Aldehyde dehydrogenase 2 in cardiac protection: a new therapeutic target? Trends Cardiovasc.Med. 2009 Jul; 19(5):158164.

9. Enomoto, N., Takase, S., Takada, N., and Takada, A. Alcoholic liver disease in heterozygotes of mutant and normal aldehyde dehydrogenase-2 genes. Hepatology. 1991 Jun; 13(6):1071-1075.

10. Sakamoto, T., Hara, M., Higaki, Y., Ichiba, M., Horita, M., Mizuta, T., Eguchi, Y., Yasutake, T., Ozaki, I., Yamamoto, K., Onohara, S., Kawazoe, S., Shigematsu, H., Koizumi, S., and Tanaka, $K$. Influence of alcohol consumption and gene polymorphisms of ADH2 and ALDH2 on hepatocellular carcinoma in a Japanese population. Int.J.Cancer. 2006 Mar 15; 118(6):1501-1507.

11. Murata, C., Watanabe, T., Furuya, H., Sugioka, Y., Mikurube, H., Yokoyama, A., Atsumi, Y., Matsuoka, K., and Okazaki, I. Aldehyde dehydrogenase 2 and beta3-adrenergic receptor gene polymorphisms: their association with elevated liver enzymes and metabolic syndrome. Metabolism. 2003 Sep; 52(9):1096-1101.

12. Chao, Y. C., Liou, S. R., Chung, Y. Y., Tang, H. S., Hsu, C. T., Li, T. K., and Yin, S. J. Polymorphism of alcohol and aldehyde dehydrogenase genes and alcoholic cirrhosis in Chinese patients. Hepatology 1994 Feb; 19(2):360-366. 
13. Guerrieri, F., Vendemiale, G., Grattagliano, I., Cocco, T., Pellecchia, G., and Altomare, E. Mitochondrial oxidative alterations following partial hepatectomy. Free Radic.Biol Med 1999 Jan; 26(1-2):34-41.

14. O'Brien, P. J., Irwin, W., Diaz, D., Howard-Cofield, E., Krejsa, C. M., Slaughter, M. R., Gao, B., Kaludercic, N., Angeline, A., Bernardi, P., Brain, P., and Hougham, C. High concordance of drug-induced human hepatotoxicity with in vitro cytotoxicity measured in a novel cell-based model using high content screening. Arch.Toxicol. 2006 Sep; 80(9):580604.

15. Smathers, R. L., Galligan, J. J., Stewart, B. J., and Petersen, D. R. Overview of lipid peroxidation products and hepatic protein modification in alcoholic liver disease. Chem.Biol.Interact. 2011 Jun 30; 192(1-2):107-112.

16. Poli, G. and Schaur, R. J. 4-Hydroxynonenal in the pathomechanisms of oxidative stress. IUBMB.Life. 2000 Oct; 50(4-5):315-321.

17. Petersen, D. R. and Doorn, J. A. Reactions of 4-hydroxynonenal with proteins and cellular targets. Free Radic.Biol.Med. 2004 Oct 1; 37(7):937-945.

18. Perez-Miller, S., Younus, H., Vanam, R., Chen, C. H., Mochly-Rosen, D., and Hurley, T. D. Alda-1 is an agonist and chemical chaperone for the common human aldehyde dehydrogenase 2 variant. Nat.Struct.Mol.Biol. 2010 Feb; 17(2):159-164.

19. Roede, J. R. and Jones, D. P. Reactive species and mitochondrial dysfunction: mechanistic significance of 4-hydroxynonenal. Environ.Mol.Mutagen. 2010 Jun; 51(5):380390.

20. Greene, A. K. and Puder, M. Partial hepatectomy in the mouse: technique and perioperative management. J.Invest Surg. 2003 Mar; 16(2):99-102.

21. von, Montfort C., Beier, J. I., Kaiser, J. P., Guo, L., Joshi-Barve, S., Pritchard, M. T., States, J. C., and Arteel, G. E. PAI-1 plays a protective role in $\mathrm{CCl} 4$-induced hepatic fibrosis in mice: role of hepatocyte division. Am.J.Physiol Gastrointest.Liver Physiol 2010 May; 298(5):G657-G666.

22. Wieckowski, M. R., Giorgi, C., Lebiedzinska, M., Duszynski, J., and Pinton, P. Isolation of mitochondria-associated membranes and mitochondria from animal tissues and cells. Nat.Protoc. 2009; 4(11):1582-1590.

23. Klingmuller, U., Bauer, A., Bohl, S., Nickel, P. J., Breitkopf, K., Dooley, S., Zellmer, S., Kern, C., Merfort, I., Sparna, T., Donauer, J., Walz, G., Geyer, M., Kreutz, C., Hermes, M., Gotschel, F., Hecht, A., Walter, D., Egger, L., Neubert, K., Borner, C., Brulport, M., Schormann, W., Sauer, C., Baumann, F., Preiss, R., MacNelly, S., Godoy, P., Wiercinska, E., Ciuclan, L., Edelmann, J., Zeilinger, K., Heinrich, M., Zanger, U. M., Gebhardt, R., Maiwald, T., Heinrich, R., Timmer, J., von Weizsacker, F., and Hengstler, J. G. Primary mouse hepatocytes for systems biology approaches: a standardized in vitro system for modelling of signal transduction pathways. Syst.Biol.(Stevenage.). 2006 Nov; 153(6):433447.

24. Atshaves, B. P., McIntosh, A. M., Lyuksyutova, O. I., Zipfel, W., Webb, W. W., and Schroeder, F. Liver fatty acid-binding protein gene ablation inhibits branched-chain fatty 
acid metabolism in cultured primary hepatocytes. J.Biol.Chem. 2004 Jul 23; 279(30):30954-30965.

25. Atshaves, B. P., Mclntosh, A. L., Payne, H. R., Gallegos, A. M., Landrock, K., Maeda, N., Kier, A. B., and Schroeder, F. SCP-2/SCP-x gene ablation alters lipid raft domains in primary cultured mouse hepatocytes. J.Lipid Res. 2007 Oct; 48(10):2193-2211.

26. Martinez, S. M., Bradford, B. U., Soldatow, V. Y., Kosyk, O., Sandot, A., Witek, R., Kaiser, R., Stewart, T., Amaral, K., Freeman, K., Black, C., LeCluyse, E. L., Ferguson, S. S., and Rusyn, I. Evaluation of an in vitro toxicogenetic mouse model for hepatotoxicity. Toxicol.Appl.Pharmacol. 2010 Dec 15; 249(3):208-216.

27. Seglen, P. O. Preparation of isolated rat liver cells. Methods Cell Biol. 1976; 13(29-81.

28. Uryvaeva, I. V., Tsitrin, E. B., Gorodetsky, S. I., Tsvetkova, I. A., Delone, G. V., Gulyaev, D. V., and Khrushchov, N. G. The phenotypic characters of the stem cells in hepatocytes during liver regeneration: the expression of the Bcrp1/Abcg2 membrane transporter and the Hoechst 33342 export. Dokl.Biol.Sci. 2004 Sep; 398:413-6.(413-416.

29. Nokubo, M., Nagy, I., Kitani, K., and Ohta, M. Characterization of the autofluorescence of rat liver plasma membranes. Biochim.Biophys.Acta. 1988 Apr 22; 939(3):441-448.

30. Sampey, B. P., Stewart, B. J., and Petersen, D. R. Ethanol-induced modulation of hepatocellular extracellular signal-regulated kinase-1/2 activity via 4-hydroxynonenal. J.Biol.Chem. 2007 Jan; \%19;282(3):1925-1937.

31. Doorn, J. A., Hurley, T. D., and Petersen, D. R. Inhibition of human mitochondrial aldehyde dehydrogenase by 4-hydroxynon-2-enal and 4-oxonon-2-enal. Chem.Res.Toxicol. 2006 Jan; 19(1):102-110.

32. Chen, C. H., Budas, G. R., Churchill, E. N., Disatnik, M. H., Hurley, T. D., and MochlyRosen, D. Activation of aldehyde dehydrogenase-2 reduces ischemic damage to the heart. Science. 2008 Sep 12; 321(5895):1493-1495.

33. Perez-Miller, S., Younus, H., Vanam, R., Chen, C. H., Mochly-Rosen, D., and Hurley, T. D. Alda- 1 is an agonist and chemical chaperone for the common human aldehyde dehydrogenase 2 variant. Nat.Struct.Mol.Biol. 2010 Feb; 17(2):159-164.

34. Beretta, M., Gruber, K., Kollau, A., Russwurm, M., Koesling, D., Goessler, W., Keung, W. M., Schmidt, K., and Mayer, B. Bioactivation of nitroglycerin by purified mitochondrial and cytosolic aldehyde dehydrogenases. J.Biol.Chem. 2008 Jun 27; 283(26):17873-17880.

35. Lowe, E. D., Gao, G. Y., Johnson, L. N., and Keung, W. M. Structure of daidzin, a naturally occurring anti-alcohol-addiction agent, in complex with human mitochondrial aldehyde dehydrogenase. J.Med.Chem. 2008 Aug 14; 51(15):4482-4487.

36. Croce, A. C., Ferrigno, A., Vairetti, M., Bertone, R., Freitas, I., and Bottiroli, G. Autofluorescence properties of isolated rat hepatocytes under different metabolic conditions. Photochem.Photobiol.Sci. 2004 Oct; 3(10):920-926.

37. Comporti, M. Lipid peroxidation and biogenic aldehydes: from the identification of 4hydroxynonenal to further achievements in biopathology. Free Radic.Res. 1998 Jun; 28(6):623-635. 
38. Budas, G. R., Disatnik, M. H., Chen, C. H., and Mochly-Rosen, D. Activation of aldehyde dehydrogenase $2(\mathrm{ALDH} 2)$ confers cardioprotection in protein kinase $\mathrm{C}$ epsilon (PKCvarepsilon) knockout mice. J.Mol.Cell Cardiol. 2010 Apr; 48(4):757-764.

39. Churchill, E. N., Disatnik, M. H., and Mochly-Rosen, D. Time-dependent and ethanolinduced cardiac protection from ischemia mediated by mitochondrial translocation of varepsilonPKC and activation of aldehyde dehydrogenase 2. J.Mol.Cell Cardiol. 2009 Feb; 46(2):278-284.

40. Zhou, H. Z., Karliner, J. S., and Gray, M. O. Moderate alcohol consumption induces sustained cardiac protection by activating PKC-epsilon and Akt. Am.J.Physiol Heart Circ.Physiol. 2002 Jul; 283(1):H165-H174.

41. Miyamae, M., Camacho, S. A., Zhou, H. Z., Diamond, I., and Figueredo, V. M. Alcohol consumption reduces ischemia-reperfusion injury by species-specific signaling in guinea pigs and rats. Am.J.Physiol. 1998 Jul; 275(1 Pt 2):H50-H56.

42. Chen, C. H., Sun, L., and Mochly-Rosen, D. Mitochondrial aldehyde dehydrogenase and cardiac diseases. Cardiovasc.Res. 2010 Oct 1; 88(1):51-57.

43. Ning, S., Budas, G. R., Churchill, E. N., Chen, C. H., Knox, S. J., and Mochly-Rosen, D. Mitigation of radiation-induced dermatitis by activation of aldehyde dehydrogenase 2 using topical alda-1 in mice. Radiat.Res. 2012 Jul; 178(1):69-74.

44. Vasiliou, V., Pappa, A., and Petersen, D. R. Role of aldehyde dehydrogenases in endogenous and xenobiotic metabolism. Chem.Biol.Interact. 2000 Dec 1; 129(1-2):1-19.

45. Hao, P. P., Chen, Y. G., Wang, J. L., Wang, X. L., and Zhang, Y. Meta-analysis of aldehyde dehydrogenase 2 gene polymorphism and Alzheimer's disease in East Asians. Can.J.Neurol.Sci. 2011 May; 38(3):500-506.

46. Shea, T. B. and Remington, R. Positive argument for debate in J Neural Transmission: Alzheimer's disease: are we intervening too late? Yes, by years if not decades. J.Neural Transm. 2012 Jul 11;

47. Kitagawa, K., Kawamoto, T., Kunugita, N., Tsukiyama, T., Okamoto, K., Yoshida, A., Nakayama, K., and Nakayama, K. Aldehyde dehydrogenase (ALDH) 2 associates with oxidation of methoxyacetaldehyde; in vitro analysis with liver subcellular fraction derived from human and Aldh2 gene targeting mouse. FEBS Lett. $2000 \mathrm{Jul}$ 7; 476(3):306-311.

48. Chen, Z., Foster, M. W., Zhang, J., Mao, L., Rockman, H. A., Kawamoto, T., Kitagawa, K., Nakayama, K. I., Hess, D. T., and Stamler, J. S. An essential role for mitochondrial aldehyde dehydrogenase in nitroglycerin bioactivation. Proc.Natl.Acad.Sci.U.S.A 2005 Aug 23; 102(34):12159-12164. 


\section{LIST OF ABBREVIATIONS}

4HNA, 4-hydroxynon-2-enoic acid; 4-HNE, 4-Hydroxynonenal, ALD, Alcoholic Liver Disease; ALDH2, Aldehyde Dehydrogenase 2; ALDH2*2, ALDH2 polymorphism; ANOVA, One-way analysis of variance; EGTA, Ethylene glycol tetraacetic acid; EtOH, Ethanol, HBSS, Hanks balanced salt solution; HCS, High Content Screening; HCC, Hepatocellular carcinoma; IMM, Inner Mitochondrial Membrane; IVC, inferior vena cava; MD, Maltose Dextrin, NAFLD, NonAlcoholic Fatty Liver Disease; PHx, Partial Hepatectomy; PUFAs, Polyunsaturated Fatty Acids; SEM, Standard error of the mean; 


\section{CURRICULUM VITAE}

\section{KEEGAN J BALDAUF}

Date of Birth: $\quad$ November 24, 1982

Email address: KJBald02@exchange.louisville.edu

\section{EDUCATION}

Master of Science, Pharmacology and Toxicology

2012 (anticipated)

University of Louisville, Louisville, KY

Bachelor of Science, Molecular Biology and Biotechnology

2005

Clarion University of Pennsylvania, Clarion, PA

\section{HONORS}

2005 Biology Day Presenter for Prospective Students

Clarion University of Pennsylvania

2009-2011

Graduate Research Fellowship, Integrated Programs in Biomedical Sciences

2010

Research! Louisville Masters Basic Science Graduate Student Award

\section{PROFESSIONAL SOCIETIES AND MEMBERSHIPS}

2001-2005

Member, Clarion Students Association (CSA) Board of Directors

2001-2005

Chairman, CSA Operations Committee

2005

Steering Committee for Concerts on Campus

2005 Chairman, CSA Board of Directors 


\section{ABSTRACTS}

Baldauf KJ, Schmidt RH, Ding X, Beier JI, Tan M, and Arteel GE (2010) Sulforaphane Enhances Liver Regeneration after Partial Hepatectomy in Mice. Hepatology 52:617A

\section{PRESENTATIONS}

$05 / 2010$

Research Seminar - "Effect of Sulforaphane on Liver Regeneration in Mice" University of Louisville Seminar in Pharmacology and Toxicology

Louisville, KY

09/2010

Poster Presentation - "Sulforaphane Enhances Liver Regeneration after Partial Hepatectomy in Mice"

Ohio Valley Society of Toxicology Annual Meeting

Cincinnati, $\mathrm{OH}$

$10 / 2010$

Poster Presentation - "Sulforaphane Enhances Liver Regeneration after Partial Hepatectomy in Mice"

Research! Louisville

Louisville, KY

$11 / 2010$

Poster Presentation - "Sulforaphane Enhances Liver Regeneration after Partial Hepatectomy in Mice."

American Association for the Study of Liver Diseases Liver Meeting

Boston, MA

09/2011

Poster Presentation - "Acetaldehyde Dehydrogenase 2 (ALDH2) activation protects hepatocytes from mitochondrial damage and death caused by 4-hydroxynonenal."

Ohio Valley Society of Toxicology Annual Meeting

Wright State University, $\mathrm{OH}$

10/2011

Poster Presentation - "Enhanced Acetaldehyde Dehydrogenase 2 (ALDH2) activity protects hepatocytes from mitochondrial damage and death caused by 4-hydroxynonenal."

Research! Louisville

Louisville, $\mathrm{KY}$

03/2012

Poster Presentation - "Dehydrogenase 2 (ALDH2) activation protects hepatocytes from mitochondrial damage and death caused by 4-hydroxynonenal.

Society of Toxicology Annual Meeting

San Francisco, CA 